agency of the sweat glands in dissipating the acids of the blood.

Ninety per cent. of the heat elaborated in the human economy, is eliminated through the skin by radiation, conduction and evaporation. In this climate (southwest Texas), during three-fourths of the year, radiation and conduction are nil so that all the 90 per cent. of heat is eliminated by evaporation of sweat, with consequent increase of blood alkalinity. Now, any sudden excessive exercise, in a gouty subject, upon the advent of intensely hot weather, will result in a fulminating uric-acidemia, with a consequent shock to the vaso-motor and trophic nervous systems, together with the symptoms, high blood pressure, diminished metabolism, retention of waste products in muscular system, headache, partial suppression of urine, urine of high color and specific gravity.

It is to the fulmination of the intense uric-acidemia that the paresis of the nervous system is due, with resultant continued fever. Children are exempt to a large extent, from this fever by reason of the fact that all of their nitrogenous ingesta is utilized in the upbuilding of tissue; officers and women by reason of their comparative sedentation and consequent exemp. tion of this fulmination of the uric-acidemia. do not suffer from inhibition of function of the vaso-motor and trophic nervous systems (fever), but do suffer to a marked extent from lithemia and neurasthenia.

I would define the affection as follows, a simple continued fever occurring in a gouty subject, primarily dependent upon a partial inhibition of function of the vaso-motor and trophic nervous systems, as a result of a fulminating uric-acidemia and physical exhaustion, consequent upon excessive and unaccustomed work or exercise, involving exposure to the intense heat of tropical or semi-tropical climates.

The limits of this article prevent an exhaustive discussion of all the facts and individual cases that might be advanced in support of my conception of the etiology of this affection. This paper is presented more as a suggestion than as a dogmatism, and while it represents my own personal convictions, yet a further study of the subject, with more elaborate methods of investigation, would be necessary before they can be accepted.

The writer has suggested the term febris auto-intoxica for reasons above indicated, but from its possible confusion with intestinal autotoxis it was withdrawn. Continued thermic fever, while a step forward, does not meet every requirement.

At the present time and in view of our uncertain ideas as regards its etiology, it is belived that "simple continued fever" expresses the condition as nearly as any.

At the time of these observations Widal's method of diagnosis had not been presented. The writer takes this opportunity of expressing from his own limited observations, his convictions of its efficacy, and with the aid of which he hopes in the future to be able to make a further study of so interesting a subject.

Prescription Taking Done to the Letter.-Abbe Huc, the renowned French explorer and missionary, says that when a Tartar doctor finds himself without his drugs and medicines, he is not in the least embarrassed. He writes the names of the needed drugs on slips of paper, and these, being rolled up in little balls, are swallowed by the sick man. "To swallow the name of a remedy, or the remedy itself," say the Tartars, "comes to precisely the same thing." - St. Nicholas.

\section{A BRIEF HISTORY OF INSANITY AND TUBERCULOSIS IN THE SOUTH. ERN NEGRO.}

BY THOS. J. McKIE, M.D. WOODLAWN. s. C.

As a further elucidation of the subject of the etiology of tuberculosis and insanity in the southern negro is not without interest to the readers of the Journal, as indicated by the able article of Dr. Powell and the discussion following, which appeared in the JourNaL of December 5 of the year just past, the following brief history is offered as a record of the rise and progress of these allied diseases in a small portion of Edgefield County, on the extreme western border of South Carolina, and lying immediately between Stevens' Creek on the east and the Savannah River on the west.

Going back to 1848 , when these observations began, it may be generally stated that tuberculosis and insanity were unknown and rarely heard of as diseases of the negro, in this section of our State; but, on the other hand, it was an admitted fact that he was peculiarly exempt from both. In 1866 the first case of tuberculosis ever seen in this locality by the writer occurred in the family of J. T. H., recently removed from the 96 section to the plantation of the late Governor Pickens, which lies in the fork of Stevens' Creek and Savannah River, nine miles above Augusta, Ga. This family (white) had already suffered a loss of several members before removal, and must therefore have brought the disease with them, or in them. No other white family has had a case.

The first case seen in the person of a southern negro happened in the family (man and wife) of J. H.. who were servants to the white family H., both of whom died, as all who have since been attacked have done. Unlike the whites these two were previously considered healthy and of pure negro blood.

The next case occurred in the person of a married woman of mixed blood living seventeen miles north of the Pickens plantation, without social or other relation with any one on it, as far as could be ascertained. Soon other families began to suffer without regard to situation or social intercourse, showing, however, a predilection for certain families, whether living far or near. Especially has this characteristic been marked in the family of the woman of mixed blood, which has been well nigh destroyed, though quite a large one. In the aggregate, more families however of pure than mixed have succumbed.

Surprised and puzzled at this sudden and unaccountably new feature in the nosological table of negro complaints, it seemed not impossible that something of the true cause of tuberculosis might be gained here in a field where hitherto it had been entirely unknown, particularly in the southern negro, and a study of the diet, habits, mode of life, etc., of these stricken families was undertaken on the surrounding plantations and has been steadily pursued through the intervening year.

During this time many theories of its etiology have been advanced without having established one fact beyond the one of its wide prevalence in a region of country where before the establishment of a new order of things its existence was not known. Repeated inquiries made among fellows of the State Medical Society at their annual meetings, establishes the fact that very many have observed this change in the 
character of disease in the negro, and many and various guesses have been made at the cause or causes that have brought it about. Among these, frequent mention has been made of scrofula and more of venereal, though neither seems to have anything to do with it, either as predisposing or exciting cause. In justice to the negro, be it said, taking into view his more limited moral training, his fewer social restraints, his unrestricted fields of social indulgence, his less refinement in the practice of vice or virtue, his want of knowledge of the baleful influence of the resulting evils, and he need not fear comparison with his more enlightened white neighbor, though both have kept comparative free from disease of this kind, contamination proving the rare exception in either. The co-existence of tuberculosis with syphilis, hereditary or otherwise, has not been observed in any case, notwithstanding the fact of a professional acquaintance with the diseases of several of these families which extends back to the days of slavery, when both ${ }^{1}$ syphilis and tuberculosis were entire strangers in the rural districts to which these observations relate

Freedom from restraint permitting freer indulgence in all manner of excess, absence of regard for hygienic law or practice, excess in eating and drinking, the want of wholesome food, especially of the accustomed ration of fat bason, have all had a place in the etiological table without sufficient reason for being there. In the ante-bellum ration, hog meat (bacon) and corn bread held first place for working people. For children, corn bread, pot liquor, milk, usually buttermilk, syrup or molasses formed the staple articles of diet, though meat (bacon) was not prohibited. Under the new dispensation, wheat bread of inferior quality and for the most part execrably prepared, took the place of corn bread (which the negro cooks as no other can ), as milk and butter did the place of bacon. Here, it was at one time thought, might be found one of the causes which gave rise to tuberculosis, but further observation proved the fact that the most thriftless, with or without the use of milk or wheat bread, the most indifferent to the forms and usages of civilized life escaped the disease.

A population of 900 to 1,200 occupying an area of territory twenty by five miles in extent, and divided into plantations of creek, river and uplands, these latter for the most part broken and hilly, compose the material from which these observations are drawn, and will compare favorably with occupants of neighboring plantations in point of general health conditions. Continuing these observations with unabated interest.it was noted that the most elegant, the most refined, well-to-do families supplied by far the greatest number of insane and tuberculous subjects. The most successful, those who seem to put forth the greatest effort to imitate the better class of their white neighbors, those living in the best houses, which are well kept and well supplied with the necessary comforts of life, are the chief if not the only sufferers. To attain this higher degree of civilization requires some ambition and far more than ordinary mental effort on the part of a people who had hitherto been totally unaccustomed to such mental strain, and who are equally unfitted either by nature, education or practice to assume these grave responsibilities, and as a consequence the penalty of an overworked nervous

i Only two cases of syphilis happening before 1865 can now be recalled one in a girl of 15 , the other a man, both on the same plantation, and contracted in Augusta, Ga. organization, never strong, but delicate and sensitive in the extreme, must naturally follow.

It is a well-known fact that the negro's perceptive faculties are little inferior to those of the lower class animals. His olfactories are delicate, his vision is keen, far surpassing that of the Caucasian, particularly in the absence of strong light and at night; nor can any epicure boast the equal of his gustatory apparatus. Mentality or cerebral excitement but tends to insanity, and, when under continuous strain as in the struggle to get forward in the world, to its cousin german, tuberculosis. At least such has been the course marked in these observations. Religious frenzy has been a frequent precursor if not a cause of insanity. Several cases can now be recalled in which fatal results have followed attacks beginning in church during religious excitement. One fatal case can also be recalled in which unsatisfactory division of crops gave rise to it.

From the observations it may be concluded that in their etiologic relations insanity and tuberculosis are allied diseases; that both tuberculosis and insanity in the Southern negro have been the outcome of an overtaxed and overworked nervous organization unfitted by nature and otherwise to bear the burden imposed by newly created necessities or environment; that insanity and tuberculosis are primarily and essentially neuroses.

\section{AN AORTA WITH A DOUBLE ARCH.}

BY D. LEE SHAW, M.D.

ASSISTANT TO THE CHAIR OF ANATOMY, RUSH MEDICAL COLLEGE. CHICAGO.

Congenital malformations of the aorta are comparatively rare. Quain divides such cases into six classes, viz.: 1 , variations in position and extent; 2 , variations of septum; 3 , variations of stems; 4, variations of arch; 5 , variations of descending portion and ductus arteriosus, and 6 , variations in number and position of branches. The most uncommon of all, are those of the fourth variety, under which the double arch will be described.

In mammals the aorta normally passes to the left side of vertebral column, arching over the root of the left lung; in birds it passes to the right; and in reptiles it divides and passes to both sides. In this instance the arch presents a reproduction of the reptilian arrangement.

This specimen was taken from a fairly well nourished, white, male subject, in the anatomic laboratory of Rush Medical College. Previous condition and cause of death is unknown. No abnormalities were found in the venous system. The heart is $12 \mathrm{~cm}$. in length, muscle normal, and the cavities are perfectly formed; no communication whatever exists between right and left sides. Pulmonary artery is normal in position and distribution, although, from its point of division, a septum $2 \mathrm{~cm}$. in length extends into the main trunk.

Arch of the aorta, ascending portion, is $2.5 \mathrm{~cm}$. in diameter and in its usual position. It divides, $3 \mathrm{~cm}$. above the pericardial attachment, into a small left branch and a large right branch. The left division, $1.5 \mathrm{~cm}$. in diameter, passes in front of the trachea, in the pasition of the normal arch; and $2 \mathrm{~cm}$. from its origin, at the left antero-lateral aspect of the trachea, gives off the left common carotid; immediately behind which the left subclavian arises. The left arterial trunk is continued by an isthmus, $.75 \mathrm{~cm}$. in diameter 